\title{
Current Scenario of Antiviral Drugs for Japanese Encephalitis
}

\author{
Shailendra K. Saxena ${ }^{1^{*}}$, Parth T. Agrawal ${ }^{1}$ and Madhavan P.N. Nair ${ }^{2}$ \\ ${ }^{1}$ CSIR-Centre for Cellular and Molecular Biology (CCMB), Uppal Road, Hyderabad, India \\ ${ }^{2}$ College of Medicine, Florida International University, USA
}

*Corresponding Author: Shailendra K Saxena, Senior Scientist (Infectious Diseases), CSIR-Centre for Cellular and Molecular Biology, Uppal Road, Hyderabad 500 007 (AP), India, Tel: +914027192630; Fax: +914027160591; 2716 0311; E-mail: shailen@ccmb.res.in; shailen1@gmail.com

Rec date: Feb 23, 2014, Acc date: Apr 29, 2014, Pub date: May 01, 2014

Copyright: ( 2014 Saxena SK, et al. This is an open-access article distributed under the terms of the Creative Commons Attribution License, which permits unrestricted use, distribution, and reproduction in any medium, provided the original author and source are credited.

\section{Current Scenario}

Japanese Encephalitis (JE) is caused by neurotropic Japanese Encephalitis Virus (JEV) which belongs to flaviviridae family and is the most important encephalitis causing virus in Asia. JEV is reported to cause 35-50 thousand cases and 10-15 thousand deaths annually [1]. Viruses belonging to the flaviviridae primarily spread through arthropod vectors, and is the major cause of one of the most fatal disease around the globe. Flaviviruses are small RNA viruses transmitted by mosquitoes and ticks. Upon entering the host, they take over host cell machinery in order to propagate and flourish. JEV generally affects small children $(<15 \mathrm{yrs})$ and elderly people ( $>65 \mathrm{yrs})$ who have weak immune system and hence are vulnerable [2]. JEV infection was initially reported in Southeast Asia but now it is affecting populations worldwide [3]. JEV leads to major outbreaks in tropical regions of Asia with China, Japan, Korea, Philippines, Southeastern Asia and India [4]. JE's mortality rate is almost $25-30 \%$. Though intensive care and support help to lower the death rate, patients still continue to suffer from JE for longer period of time. Some effects such as learning difficulties and behavioral problems can remain masked for several years. From total JE infected patients, nearly one-third die and half of the survivors are left with irreversible neurological damages [5]. Around three billion people are residing in risk prone areas without any vaccination and the number of unvaccinated individuals is continuously increasing. Viruses have evolved various mechanisms to disrupt the host immune system. One important amongst them is preventing the infected cells from sending out chemotactic signals to activate the adaptive immune response. Subsequently, there is a burning need for the development of novel therapeutic drugs against JE.

There are many promising candidates against JE infection which need further assessment and increased availability to the needful. Nitazoxanide (NTZ) is a thiazolide anti-infective which is validated to have antiviral properties [6,7] and is used for the treatment of parasitic gastroenteritis. Combination of $\mathrm{N}$-methylisatin- $\beta$-thiosemicarbazone derivative (SCH16) with ribavirin and mycophenolic acid demonstrates the antiviral activity of SCH16 against JE in vitro [8]. Griffithsin (GRFT) is a broad spectrum antiviral protein that is effective against several glycosylated viruses which may be used for therapeutic development against JEV or other flaviviruses [9]. Bispidine, an amino acid conjugate of 3,7-diazabicyclo[3.3.1]nonane acts as a molecular scaffold for the development of potent antivirals against encephalitic viruses [10]. Tilapia hepcidin (TH) $1-5$, an antimicrobial peptide can control JEV viral infection and could be a promising antiviral candidate [11]. Mycophenolic acid is reported to inhibit the replication of JEV in mouse model experiments, therefore could be used against JEV infection [12]. Minocycline acts as neuroprotective agent in various animal studies of a number of acute CNS injuries, neurodegenerative disorders and CNS infection. It is reported to reduce the neuronal damage by JEV in cell culture models by inhibiting oxidative stress [13]. Studies have shown that pentoxifylline acts as antiviral against several RNA and DNA viruses. In vivo studies have shown that pentoxifylline at a concentration of $100 \mathrm{mg} / \mathrm{kg}$ body weight can protect mice introduced to LD (50) of JEV [14]. Rosmarinic acid is reported to reduce mice mortality infected with JEV [15]. Short interfering RNA (siRNA) can be used as a broad spectrum antiviral agent for treating encephalitis caused by multiple flaviviruses like JEV, West Nile virus, tick-borne encephalitis virus [16]. Dehydroepiandrosterone (DHEA) is an adrenal derived steroid which involves in protection against neurotoxicity and viral induced encephalitis, resulting in a better survival rate of the animals [17]. A low molecular weight dithiol, Diethyldithiocaramate (DDTC) is an immunomodulator and modifier of different biological actions in animal and human models. It is also effective in several disease conditions. Many experiments have shown that DDTC have a possible therapeutic role during JEV infection [18]. It has been studied that macrophage derived neutrophil chemotactic factor (MDF) induces production of nitric oxide (NO) during JEV infection, which has an antiviral effect. NO may play a crucial role in the innate immunity of the host to restrict the initial stage of JEV infection in the central nervous system $[19,20]$. Several kinds of furanonaphthoquinone (FNQ) derivatives have antiviral activity against JEV. FNQ3 inhibits JEV replication through attacking viral RNA and protein synthesis [21].

Isatis indigotica is a herb which grows in China and is traditionally used for the clinical treatment of viral diseases like encephalitis, hepatitis and influenza. Pretreatment of I.indigotica extracts, indirubin and indigo significantly inhibit JEV replication in vitro. They obstruct JEV attachment and hence have potent antiviral activity [22]. Rheum palmatum is another Chinese traditional herb which exhibits a great variety of anticancer and anti-viruses properties. Methanol extract of R.palmatum and chrysophanol may have high therapeutic index as antiviral against JEV [23]. Pokeweed antiviral protein (PAP) is a plant derived N-glycosidase ribosomal inactivating protein isolated from Phytolacca americana. PAP possesses antiviral activity against JEV infection making it promising antiviral agent [24]. Aloe-emodin is a potential interferon inducer produced from Chinese herbal medicines and is reported for antiviral activity against JE [25]. Kaempferol is a natural flavonol which acts as antiviral agent as it inactivates virus by binding with JEV frame shift site RNA (fsRNA) [26]. Lactoferrin is a natural anti-microbial protein which attaches to cell surface expressed heparan sulfate, one potential receptor for JEV, and has anti-JEV activity [27]. Astragali Radix extracts (AE) has protective effect by intraperitoneal injection against JEV infection. The studies of the mice model experiment show that the protective effect of $\mathrm{AE}$ is dependent on a non-specific mechanism during the early stage of infection, 
before it moves to antibody production and peritoneal exudate cell (PEC) plays an important role [28].

Another promising field is nanotherapeutics. Nanomaterials have the characteristic of high surface-to-volume ratio and have been discovered for their antiviral activities. Success in synthesizing surfactant-modified nanoscale silicate platelet (NSP) with antiviral activity may open doors towards future antiviral developments, for example, Nanoscale silicate platelet modified with sodium dodecyl sulfate (NSQc), functions as a potent and safe antiviral nanohybrid against many viruses [29].

Efforts for flaviviral drug research and development are growing at fast pace. Drug designing against the NS2B and NS3 nonstructural proteins of flaviviruses are being attempted. This design focuses on vital physiochemical and biochemical properties of proteases by using crystallography based models of NS3 substrate interaction compounds. Efforts are being employed to target the capping enzyme and E and NS5 proteins of flaviviruses. Crystal structure of enzymatically active domains of these nonstructural protein inhibitors has been interpreted by research to understand its sub cellular localization, biochemical properties, regulation and to design specific inhibitors that would change the kinetics of these proteins. To fight against the flaviviral infections an organized and collaborative approach is needed with contributions from clinicians, researchers, drug developers, policy makers and local population.

\section{Acknowledgments}

Authors are grateful to Director, CCMB and Council of Scientific and Industrial Research (CSIR-CCMB), India for the encouragement and support for this work. We thank Ms. Sneham Tiwari for critical reading of the manuscript. SKS and MPN are also supported by NIH Awards (R37DA025576; R01MH085259).

\section{References}

1. Le Flohic G, Porphyre V, Barbazan P, Gonzalez JP (2013) Review of climate, landscape, and viral genetics as drivers of the Japanese encephalitis virus ecology. PLoS Negl Trop Dis 7: e2208.

2. Griffiths MJ, Lemon JV, Rayamajhi A, Poudel P, Shrestha P, et al. (2013) The functional, social and economic impact of acute encephalitis syndrome in Nepal--a longitudinal follow-up study. PLoS Negl Trop Dis 7: e2383.

3. Liu WJ, Zhu M, Pei JJ, Dong XY, Liu W, et al. (2013) Molecular phylogenetic and positive selection analysis of Japanese encephalitis virus strains isolated from pigs in China. Virus Res 178: 547-552.

4. Srivastava S, Khanna N, Saxena SK, Singh A, Mathur A, et al. (1999) Degradation of Japanese encephalitis virus by neutrophils. Int J Exp Pathol 80: 17-24.

5. Sarkar A, Taraphdar D, Mukhopadhyay SK, Chakrabarti S, Chatterjee S et al. (2012) Molecular evidence for the occurrence of Japanese encephalitis virus genotype I and III infection associated with acute encephalitis in patients of West Bengal, India, Virol J 9:271.

6. Shi Z, Wei J, Deng X, Li S, Qiu Y, et al. (2014) Nitazoxanide inhibits the replication of Japanese encephalitis virus in cultured cells and in a mouse model. Virol J 11: 10.

7. Kundu K, Dutta K, Nazmi A, Basu A (2013) Japanese encephalitis virus infection modulates the expression of suppressors of cytokine signaling (SOCS) in macrophages: implications for the hosts' innate immune response. Cell Immunol 285: 100-110.

8. Sebastian L, Desai A, Yogeeswari P, Sriram D, Madhusudana SN, et al. (2012) Combination of N-methylisatin- $\hat{I}^{2}$-thiosemicarbazone derivative (SCH16) with ribavirin and mycophenolic acid potentiates the antiviral activity of SCH16 against Japanese encephalitis virus in vitro. Lett Appl Microbiol 55: 234-239.

9. Ishag HZ, Li C, Huang L, Sun MX, Wang F, et al. (2013) Griffithsin inhibits Japanese encephalitis virus infection in vitro and in vivo. Arch Virol 158: 349-358.

10. Haridas V, Rajgokul KS, Sadanandan S, Agrawal T, Sharvani V, et al. (2013) Bispidine-amino acid conjugates act as a novel scaffold for the design of antivirals that block Japanese encephalitis virus replication. PLoS Negl Trop Dis 7: e2005.

11. Huang HN, Rajanbabu V, Pan CY, Chan YL, Hui CF, et al. (2011) Modulation of the immune-related gene responses to protect mice against Japanese encephalitis virus using the antimicrobial peptide, tilapia hepcidin 1-5. Biomaterials 32: 6804-6814.

12. Sebastian L, Madhusudana SN, Ravi V, Desai A (2011) Mycophenolic acid inhibits replication of Japanese encephalitis virus. Chemotherapy 57: 56-61.

13. Mishra MK, Ghosh D, Duseja R, Basu A (2009) Antioxidant potential of Minocycline in Japanese encephalitis virus infection in murine neuroblastoma cells: correlation with membrane fluidity and cell death. Neurochem Int 54: 464-470.

14. Sebastian L, Desai A, Madhusudana SN, Ravi V (2009) Pentoxifylline inhibits replication of Japanese encephalitis virus: a comparative study with ribavirin. Int J Antimicrob Agents 33: 168-173.

15. Swarup V, Ghosh J, Ghosh S, Saxena A, Basu A (2007) Antiviral and antiinflammatory effects of rosmarinic acid in an experimental murine model of Japanese encephalitis. Antimicrob Agents Chemother 51: 3367-3370.

16. Kumar P, Lee SK, Shankar P, Manjunath N (2006) A single siRNA suppresses fatal encephalitis induced by two different flaviviruses. PLoS Med 3: e96.

17. Chang CC, Ou YC, Raung SL, Chen CJ (2005) Antiviral effect of dehydroepiandrosterone on Japanese encephalitis virus infection. J Gen Virol 86: 2513-2523.

18. Saxena SK, Mathur A, Srivastava RC (2003) Inhibition of Japanese encephalitis virus infection by diethyldithiocarbamate is independent of its antioxidant potential. Antivir Chem Chemother 14: 91-98.

19. Saxena SK, Singh A, Mathur A (2000) Antiviral effect of nitric oxide during Japanese encephalitis virus infection. Int J Exp Pathol 81: 165-172.

20. Lin YL, Huang YL, Ma SH, Yeh CT, Chiou SY, et al. (1997) Inhibition of Japanese encephalitis virus infection by nitric oxide: antiviral effect of nitric oxide on RNA virus replication. J Virol 71: 5227-5235.

21. Takegami T, Simamura E, Hirai K, Koyama J (1998) Inhibitory effect of furanonaphthoquinone derivatives on the replication of Japanese encephalitis virus. Antiviral Res 37: 37-45.

22. Chang SJ, Chang YC, Lu KZ, Tsou YY, Lin CW (2012) Antiviral Activity of Isatis indigotica Extract and Its Derived Indirubin against Japanese Encephalitis Virus. Evid Based Complement Alternat Med 2012: 925830.

23. Chang SJ, Huang SH, Lin YJ, Tsou YY, Lin CW (2014) Antiviral activity of Rheum palmatum methanol extract and chrysophanol against Japanese encephalitis virus. Arch Pharm Res .

24. Ishag HZ, Li C, Huang L, Sun MX, Ni B, et al. (2013) Inhibition of Japanese encephalitis virus infection in vitro and in vivo by pokeweed antiviral protein. Virus Res 171: 89-96.

25. Lin CW, Wu CF, Hsiao NW, Chang CY, Li SW, et al. (2008) Aloeemodin is an interferon-inducing agent with antiviral activity against Japanese encephalitis virus and enterovirus 71. Int J Antimicrob Agents 32: 355-359.

26. Zhang T, Wu Z, Du J, Hu Y, Liu L, et al. (2012) Anti-Japaneseencephalitis-viral effects of kaempferol and daidzin and their RNAbinding characteristics. PLoS One 7: e30259.

27. Chien YJ, Chen WJ, Hsu WL, Chiou SS (2008) Bovine lactoferrin inhibits Japanese encephalitis virus by binding to heparan sulfate and receptor for low density lipoprotein. Virology 379: 143-151.

28. Kajimura K, Takagi Y, Ueba N, Yamasaki K, Sakagami Y, et al. (1996) Protective effect of Astragali Radix by intraperitoneal injection against 
Citation: Saxena SK, Agrawal PT, Nair MPN (2014) Current Scenario of Antiviral Drugs for Japanese Encephalitis. J Med Microb Diagn 3: 133. doi:10.4172/2161-0703.1000133

Page 3 of 3

Japanese encephalitis virus infection in mice. Biol Pharm Bull 19 855-859.
29. Liang JJ, Wei JC, Lee YL, Hsu SH, Lin JJ, et al. (2014) Surfactantmodified nanoclay exhibits an antiviral activity with high potency and broad spectrum. J Virol 88: 4218-4228. 